\title{
ESTUDO DA PRÁTICA PEDAGÓGICA NA FORMAÇÃO DE ENFERMEIROS COM USO DE UMA GROUNDED THEORY
}

\section{PEDAGOGICAL PRACTICE STUDY IN NURSING TRAINING USING A GROUNDED THEORY}

\author{
Angela Gilda Alves ${ }^{1}$ \\ Cleusa Alves Martins ${ }^{2}$ \\ Eurides Santos Pinho ${ }^{3}$ \\ Gabriela Camargo Tobias ${ }^{4}$ \\ Maria Alves Barbosa ${ }^{5}$
}

\begin{abstract}
Resumo: Trata-se de um estudo descritivo a partir do uso da metodologia da Grounded Theory, traduzida para português como Teoria Fundamentada nos Dados (TFD). Na coleta de dados foi aplicado um questionário semiestruturado com 22 enfermeiros professores integrantes de seis instituições de ensino superior no período de agosto a dezembro de 2015. A análise e a interpretação dos conteúdos transcritos foram desenvolvidas de acordo com a proposta metodológica da TFD e utilizou-se o software ATLAS/ti como suporte às interpretações e organização documental. A análise dos dados resultou em quatro subcategorias: formação docente do enfermeiro; processo ensino-aprendizagem; metodologias e estratégias de ensino e as interfaces das tendências progressistas - crítico social dos conteúdos. Este estudo permitiu concluir que o método da TFD é relevante para a análise qualitativa, por seu rigor analítico e metodológico, e tem contribuído significativamente para expansão do conhecimento a qual permite tratar a abordagem de forma interpretativa e sistemática.
\end{abstract}

Palavras-chave: Análise de dados; Prática pedagógica; Pesquisa qualitativa; Teoria fundamentada.

Abstract: This is a descriptive study using the Grounded Theory methodology, translated into Portuguese as Teoria Fundamentada nos Dados (TFD). In the data collection, a semi-structured questionnaire was applied with 22 teaching nurses from six higher education institutions from August to December 2015. The analysis and interpretation of the transcribed contents were developed according to the GT methodological proposal. The ATLAS/ti software was used as support for interpretations and documentary organization.

\footnotetext{
${ }^{1}$ Mestre em Ensino na Saúde pela Universidade Federal de Goiás (UFG). Coordenadora do Departamento de Enfermagem da Faculdade Sul-Americana (FASAM), Goiânia, Goiás, Brasil. E-mail: angelagildaalves@gmail.com

${ }^{2}$ Doutora em Enfermagem pela Universidade Federal de Goiás (UFG). Professora Associada da Faculdade de Enfermagem da Universidade Federal de Goiás (UFG), Goiânia, Goiás, Brasil. E-mail: cleusa.alves@gmail.com

3 Mestre em Saúde Coletiva pela Universidade Federal de Goiás (UFG). Professora adjunto do Departamento de Enfermagem da Faculdade Sul-Americana (FASAM), Goiânia, Goiás, Brasil. E-mail: euridesenf@gmail.com

${ }^{4}$ Doutora em Epidemiologia pela Universidade Federal de Goiás (UFG). Professora adjunto do Departamento de Enfermagem da Faculdade Sul-Americana (FASAM), Goiânia, Goiás, Brasil. E-mail: gabicamargo22@gmail.com

${ }_{5}^{5}$ Doutorado em Enfermagem pela Universidade de São Paulo (USP). Atualmente é professora Associada, Nível III na Faculdade de Enfermagem da Universidade Federal de Goiás. É professora orientadora do Programa de Pós-Graduação em Ciências da Saúde da Faculdade de Medicina e do Programa de PósGraduação em Enfermagem, ambos da Universidade Federal de Goiás (UFG), Goiânia, Goiás, Brasil. Email: maria.malves@gmail.com
} 
The data analysis resulted in four subcategories: Nurses teacher-training; Teaching-learning process; Teaching methodologies and strategies, and the interfaces of progressive trends - social critical of content. This study allowed us to conclude that the GT method is relevant to the qualitative analysis, due to its analytical and methodological rigor, and has contributed significantly for the expansion of the knowledge that permits to treat the approach in an interpretative and systematic way.

Keywords: Data analysis; Pedagogical practice; Qualitative reserach; Grounded theory.

\section{Introdução}

A formação de enfermeiros capazes de atender as necessidades de saúde da população de maneira crítica e reflexiva é um desafio emergente. Nesse cenário, os professores desenvolvem papel fundamental como mediadores do processo formativo por meio da sua prática pedagógica. Para isso, a compreensão dos docentes sobre a sua prática da pedagógica é substancial para a coerência da escolha de metodologias de ensino que favoreçam o desenvolvimento de competências. A inadequação entre esses elementos pode dificultar o aprendizado, comprometer o desenvolvimento de competências e gerar desgastes na relação professor-aluno.

A docência no Ensino Superior, na busca de contribuir com o ensino de qualidade, questiona, principalmente, a formação e atuação no desenvolvimento pedagógico de professores. A formação do Bacharel Enfermeiro contém poucas disciplinas que abordam a atuação na área da docência, o preparo do profissional é voltado para áreas específicas da saúde, seja para atuar na atenção básica de saúde ou em nível hospitalar.

É evidente a demanda de buscar o aperfeiçoamento de estratégias utilizadas no Ensino Superior, o repensar quanto ao relacionamento entre docente e discente, além da possibilidade da mediação pela possível troca de experiências no ambiente acadêmico (PESSOA; MACEDO, 2018).

A prática docente pode ser abordada em duas dimensões para a formação profissional do professor com vista ao desenvolvimento didático a ser aplicado em sala de aula. No Brasil, houve expansão no campo de trabalho para o professor enfermeiro, evidenciada pelo aumento do número de escolas de enfermagem, assim, faz-se necessário discutir aspectos referentes à prática docente (SILVA et al., 2012; LIBÂNEO, 2013).

Segundo Fazenda (2013), compreender a prática docente implica em atitude de reciprocidade, troca com seus pares e consigo mesmo, é ter a consciência da sua limitação, do próprio saber e a vontade maior de desvendar novos saberes. Mais que atitude, descreve a memória como a mola que impulsiona e faz instigar a revisão e releitura crítica da prática docente. 
A prática em sala de aula exige do professor o entendimento de como acontece e se constrói a aprendizagem na vida do ser humano. Para que haja a compreensão desse processo, é necessário que o professor crie vínculos afetivos com seus alunos, tenha o entendimento de que o aluno é um ser repleto de ideias, experiências próprias e precisa ser escutado para a construção de seu conhecimento (LIBÂNEO, 2013).

Para analisar o contexto da prática docente, se faz necessário utilizar um método que permita chegar a um modelo conceitual, por meio do desenvolvimento e relacionamento de conceitos, além da compreensão do fenômeno que deve emergir dos dados e não de conceitos pré-formados. Nesse sentido a Teoria Fundamentada em Dados tem enfoque qualitativo que concebe a ideia ou conceito baseado em um esquema lógico e explicativo acerca dos fenômenos os quais apresentam relação entre os processos indutivos que elaboram conceitos a partir dos dados e processos dedutivos através das hipóteses que se relacionam aos conceitos (STRAUSS; CORBIN, 2008).

Diante do exposto, questiona-se: Qual a contribuição da Teoria Fundamentada em Dados para análise de dados e formulação de modelo conceitual que represente a prática docente no curso de graduação em enfermagem na perspectiva histórico-cultural?

Tem-se que a TFD é uma ferramenta relevante no processo de análise e significação dos dados. Por permitir o reconhecimento de um tema ou teoria conceitual que justifique elemento investigado. Com isso, esse trabalho tem como objetivo relatar a experiência da utilização da TDF no processo de análise dos dados.

\section{Referencial teórico}

A Teoria Fundamentada nos Dados (TFD) foi desenvolvida pelos sociólogos Barney Glaser, da Universidade de Columbia e Anselm Strauss, da Universidade de Chicago, na década de 1960, portanto está fundamentada na Sociologia, com influência do Interacionismo Simbólico (IS) e do pragmatismo. Sua utilização como método de pesquisa teve publicação a partir de 1967 e se estende até atualidade (COSTA, 2013; GLASER; STRAUSS, 1967).

Assim, teve origem a TFD, cuja sistematização técnica e procedimentos de análise capacitam o pesquisador para desenvolver teorias sociológicas sobre o mundo da vida dos indivíduos, uma vez que alcança significação, compatibilidade entre teoria e observação, capacidade de generalização e reprodutibilidade, precisão, rigor e verificação (STRAUSS; CORBIN, 2008). 
A versão straussiana oferece um método mais estruturado e um conjunto de ferramentas que ajuda a sensibilizar o investigador para a descoberta de novos conceitos e é caracterizada pelo equilíbrio entre a subjetividade e a objetividade (FREITAS; BANDEIRA DE MELO, 2012).

Esse constitui um processo que requer rigor metodológico que poderá resultar, desde a organização de conceitos até a formulação de um modelo teórico, dependendo do nível de complexidade da análise atribuída, no fenômeno em estudo. Dessa forma, compreende-se que a teoria proveniente dos dados é agregada ou relacionada a outras teorias, podendo acrescentar ou trazer novos conhecimentos à área do fenômeno (CASSIANI; CALIRI; PELÁ, 1996).

A TFD tem enfoque qualitativo que concebe a ideia ou conceito baseado em um esquema lógico e explicativo acerca dos fenômenos os quais apresentam relação entre os processos indutivos que elaboram conceitos a partir dos dados e processos dedutivos através das hipóteses que se relacionam aos conceitos (STRAUSS; CORBIN, 2008).

A intenção dessa teoria é descobrir um modelo conceitual que explique o fenômeno a ser investigado e possibilite ao investigador desenvolver e relacionar conceitos, cuja ênfase está na compreensão do fenômeno tal como ele emerge dos dados e não no embasamento em conceitos e teorias do pesquisador (CASSIANI; CALIRI; PELÁ, 1996; CHENITZ; SWANSON, 1986).

Complementando tais concepções, a TFD compreende a realidade a partir do conhecimento da percepção ou significado que certo contexto ou objeto tem para a pessoa. Consiste em método para construção de teoria com base nos dados investigados de determinada realidade, de maneira indutiva ou dedutiva que, mediante a organização em categorias conceituais, possibilita a explicação do fenômeno investigado (STRAUSS; CORBIN, 2008; CASSIANI; CALIRI; PELÁ, 1996).

A aplicação do método poderá iniciar-se pela microanálise, necessária para gerar as categorias no estudo. Na sequência, as codificações são realizadas e passam a sugerir relações entre essas, em um processo de constante comparação. A codificação é a parte central da análise dos dados e o processo de codificação se organiza em três etapas: codificação aberta, codificação axial e codificação seletiva (COSTA, 2013; STRAUSS; CORBIN, 2008; BANDEIRA DE MELO, 2006).

Charmaz (2009) afirma a abordagem mais recente da TFD, que recomenda três tipos de codificação: 'Codificação inicial', a qual fragmenta os dados em palavras, linhas ou segmentos de dados e implica em transcrever todo o material coletado e as frases 
analisadas e selecionar as palavras-chave. Ao longo de todas essas fases são construídos os memorandos ou "memos"; 'Codificação focalizada' utiliza os códigos ou categorias iniciais mais significativas ou frequentes para classificar, sintetizar, integrar e organizar quantidades enormes de dados; 'Codificação axial' específica as propriedades e as dimensões de uma categoria, ao relacionar as categorias às subcategorias e reagrupar dados que foram fragmentados durante a codificação inicial para dar coerência à análise emergente.

\section{Metodologia}

Trata-se de um estudo descritivo exploratório do uso da metodologia da Grounded Theory. A coleta de dados foi realizada no período de agosto a dezembro de 2015, por meio de entrevistas à 22 Enfermeiros Professores integrantes do Núcleo de Saúde Pública das disciplinas de Saúde da Mulher, Saúde da Criança e Saúde Coletiva, de seis Instituições de Ensino Superior.

Para a coleta de dados foi utilizada entrevista semiestruturada com questões abertas. A análise e a interpretação dos conteúdos transcritos produzidos foram desenvolvidas de acordo com a proposta metodológica da Teoria Fundamentada nos Dados.

A análise dos dados consistiu em uma fase central da TFD, para isso utilizou-se o software ATLAS/ti como suporte às interpretações e organização documental, uma alternativa viável no desenvolvimento da análise, principalmente, por permitir a análise e apresentação dos resultados e possibilitar a construção de redes semânticas.

O percurso metodológico dividiu-se estrategicamente em três níveis: o primeiro nível, definido como descrição, busca a identificação dos códigos que correspondeu à Microanálise - Codificação Aberta, seguida de uma leitura criteriosa do tipo linha a linha das entrevistas, e os códigos considerados relevantes foram construídos em grande escala, totalizando 102 códigos. Na Codificação Aberta os dados foram resgatados às solicitações que provêm dos mesmos. Nesse prisma, é aberta no sentido de que a codificação promoveu o despertar, abriu os dados e explorou partes das entrevistas para emergir todos os significados possíveis que o texto pode originar. Desse modo, a codificação "in vivo" das características e detalhes deram consistência às falas proferidas por professores participantes. 
Os códigos selecionados e definidos pela pesquisadora foram cadastrados no software Atlas.ti e, a partir desses, uma nova busca foi realizada, usando o código na íntegra e seus respectivos sinônimos a fim de que nenhum dado fosse perdido.

No segundo nível, ocorreu o agrupamento dos códigos por semelhança e/ou proximidade e originaram-se as subcategorias que reuniram o núcleo de sentido seguindo o ordenamento conceitual dos códigos. Posteriormente, emergiram as categorias que deram sustentação para facilitar a discussão da Codificação Axial, em que há predomínio da dedução. Pode-se dizer que a conexão entre as categorias classificadas, segundo o contexto, deriva de interações e deram sentido ao fenômeno.

Para o agrupamento no software, foram criadas as famílias que correspondem à codificação axial. Todas as subcategorias foram vinculadas até obter-se a saturação dos dados, ou seja, refinamento e interconexão, em que os códigos se repetiam e os semelhantes foram recodificados por meio de análise minuciosa. Assim, o número de códigos se reduziu a 20 e, em alguns casos, foram renomeados sem prejuízo da sua semântica para garantir um sentido condizente com os dados e com as categorias emergentes. E, nomearam-se as categorias, utilizando a criatividade a qual permite a TFD.

Para auxiliar no processo de codificações aberta e axial, os dados foram lançados no software ATLAS/ti 7.0, em que se viabilizou a organização do grande volume de material transcrito permitindo codificá-lo (codes) e visualizar os resultados em categorias (families) que foram interligadas, e possibilitar o agrupamento dos códigos e categorias em redes semânticas. Os codes, identificados no material transcrito, são as quotations que foram trechos dos relatos que apresentaram o codedefinido.

De acordo com Silva et al., (2015) a utilização do software foi descrita como instrumento para encontrar núcleos de sentido nos dados apresentados, como redes semânticas, verificando sua frequência relacionada ao objetivo do estudo.

Por fim, o terceiro nível, definido como teorização, importante para revelar a Codificação Seletiva e consequentemente a Teoria Substantiva, advinda do refinamento, integração e inter-relação das categorias, consiste no tema central que representa e remete aos dados analisados. Conceito organizador principal de uma área da pesquisa identificado indutivamente seguindo a hierarquização das categorias.

Nesse nível da Teoria surgiram os sinais de plasticidade, partindo para o plano abstrato e indutivo. Caracteriza-se como uma fase não linear, feita de intuições baseadas nos dados. Nesse momento, revisitou-se o banco de dados para confirmar e validar a teoria emergente, verificou-se que o tema central esteve presente desde a codificação 
aberta, persistindo em todos os níveis e refinamentos realizados acerca da prática docente no ensino na saúde.

A categoria central é aquela capaz de reunir outras categorias para formar um todo explanatório a qual formou um eixo temático único com informações dos participantes, a fim de subsidiar a elaboração, execução e supervisão referentes à prática docente denominada categoria emergente.

\section{Discussão}

A coleta de dados na TFD, adotada neste estudo, ocorreu por meio de entrevistas e observações. A entrevista permitiu flexibilidade para esclarecer pontos essenciais para a compreensão da realidade investigada e avaliar a consistência dos relatos, mediados pela observação do comportamento não verbal do participante, que permite compreender o que não é passível de expressão. Assim, à medida que os dados foram coletados, foram submetidos à análise concomitante, em um processo de comparação constante (DANTAS et al., 2009).

Existem na TFD, três níveis de análise, também aqui executados, no processo de construção teórico, sendo: a descrição ou codificação aberta, o ordenamento ou codificação axial conceitual e a teorização ou codificação seletiva (STRAUSS; CORBIN, 2008). Os níveis das diretrizes da teoria fundamentada descritos por Charmaz (2009) são as etapas do processo de pesquisa, que fornecerem caminho para que se possa modelar e remodelar os dados coletados num processo de refinamento dos dados.

No nível de descrição ou codificação aberta a partir dos discursos dos participantes, ocorreram a análise criteriosa e a organização das informações segundo a Teoria Fundamentada nos Dados, para refinamento dos códigos. Assim, a 'descrição' se deu a partir da elaboração de aspectos realidade de maneira informativa e cuidadosa. Ao incorporar conceitos, os detalhes descritivos e pelo menos implicitamente, não possui interpretações acerca do porquê, nem como o fenômeno ocorre (COSTA, 2013).

Enquanto o ordenamento conceitual ou codificação axial é o nível considerado precursor da teorização, em que os dados são organizados em categorias (STRAUSS; CORBIN, 2008). Nessa etapa os dados provenientes da reflexão dos participantes quanto à prática docente cotidiana e os reflexos no processo ensino em enfermagem, foram ordenados conceitualmente e refinou-se a categoria "A prática docente do enfermeiro à 
luz da teoria histórico-cultural" da qual derivaram as subcategorias intervenientes a essa prática, conforme apresentado na Figura 1.

Figura 1: Apresentação da categoria, das subcategorias e da teoria que emergiram da Teria Fundamentada nos Dados.

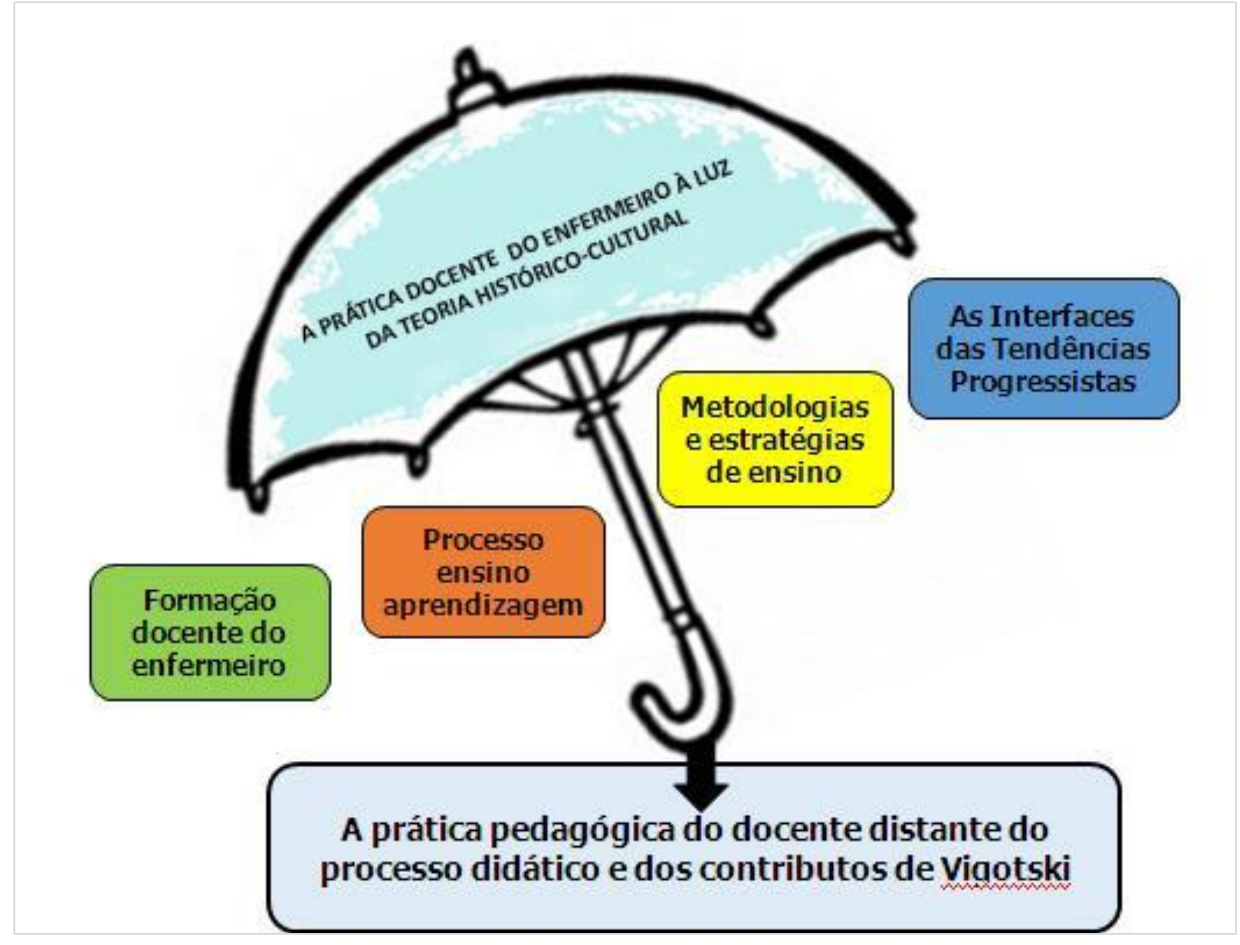

Fonte: Análise de dados das autoras.

A partir da categoria central, as subcategorias são também refinadas de modo a propor o entendimento de que a prática docente do enfermeiro à luz da teoria históricocultural é temática central que envolve temas mais específicos que necessitam ser investigados, tais como: formação docente do enfermeiro; processo ensinoaprendizagem; metodologias e estratégias de ensino; as interfaces das tendências progressivas formação. O resultado da análise e imersão nos dados resulta em uma teoria substantiva, a prática pedagógica do docente distante do processo disático e dos contributos de Vigotski.

Nessa lógica tem-se a 'codificação aberta', que parte da decomposição, análise, comparação, conceitualização e categorização dos dados. Nessa etapa, os dados ganham vida a partir dos questionamentos que emergem, são descobertas propriedades e dimensões das categorias, e os incidentes ou eventos são agrupados em códigos, conceitos, através da comparação incidente-incidente. A intenção é realizar amostragens 
teóricas suficientes e ter as evidências necessárias para formar uma categoria conceitual fundamentada nos dados (COSTA, 2013; BANDEIRA DE MELO, 2006).

A partir da identificação de categorias conceituais pela codificação aberta, a 'codificação axial' examina as relações entre categorias e subcategorias. A categoria representa o fenômeno que emerge, enquanto a subcategoria responde a questões do fenômeno. Explicitam-se causas e efeitos, condições intervenientes e estratégias de ação, em proposições que devem ser testadas novamente nos dados (COSTA, 2013; BANDEIRA DE MELO, 2006; STRAUSS; CORBIN, 1998).

Tarozzi (2011) afirma que um bom sistema de análise é definir as relações hierárquicas entre as categorias, para identificar subcategorias irmãs e subcategorias filhas. Assim, aquelas que demonstraram relação de paridade hierárquica foram colocadas sob o guarda-chuva de uma categoria conceitualmente mais extensa.

O processo envolve a identificação de itens nos dados, além de anunciar uma definição de acordo com as suas características e dimensões. Essas classificações são analisadas de forma temática, por estágios ou por tipos de pessoas e ações. A análise é fundamental para o nível ou diretriz denominados teorização, pois uma teoria contém conceitos definidos de acordo com suas características e dimensões. A organização de conceitos, contudo, pode constituir o objetivo desejado em algumas investigações e não a integração desses conceitos em uma teoria (STRAUSS; CORBIN, 2008).

Nesse sentido, a subcategoria Formação Docente do Enfermeiro por meio da organização dos conceitos referidos pelos participantes demonstrou resultados que indicam que a formação do enfermeiro docente pode permear diversos caminhos desde a graduação até ao constante processo de agregar conhecimento ao longo da sua prática profissional. Ainda que existam recomendações quanto à formação em licenciatura ou outros cursos formativos na área da docência, não há um padrão definido ou um único caminho a ser seguido.

Seguindo a segunda subcategoria Processo Ensino-Aprendizagem surgiu a partir dos dados que sinalizaram as características que o envolveram e que podem influir positiva ou negativamente. Esse processo pode ser permeado de diversas maneiras e sofre inúmeras influências na visão do professor enfermeiro. Os dados apresentados são reflexos da realidade do ensino em enfermagem e de suas interferências.

Enquanto os códigos que orientaram a subcategoria Metodologias: Estratégias de Ensino-aprendizagem, referem aos procedimentos de ensino e recursos didáticos, que foram descritos como estratégias de ensino, por não estarem compreendidos no contexto 
de metodologia. As pontuações referentes a metodologias e estratégias de ensino surgiram com número relevante de ocorrência nas falas conforme a descrição dos professores.

A Interface das Tendências Progressistas, foi a subcategoria que discutiu a interface das tendências progressistas crítico social dos conteúdos, a partir da vivência relatada pelos participantes. Em suma, os dados pertinentes a essa discussão foram organizados, por ordem de ocorrência nas entrevistas para direcionar a discussão até emersão da Teoria Substantiva em que consiste o nível de teorização.

A teorização caracteriza-se pelo conjunto de categorias ou conceitos interrelacionados de forma sistemática, através de enunciados de relação, formando um quadro que explica um fenômeno. Vale ressaltar que se trata de um processo em construção que se inicia na transição e organização dos conceitos para a elaboração da relação entre eles (STRAUSS; CORBIN, 2008).

Finalmente, a 'codificação seletiva' refina todo o processo, identificando a categoria central da teoria, com a qual todas as outras estão relacionadas. A categoria central deve ser capaz de integrar todas as outras categorias e expressar a essência do processo social que ocorre entre os envolvidos. O processo de codificação seletiva subsidiará a formação de um esquema organizacional maior, e os resultados compõem a teoria. Ainda na codificação seletiva, categorias mal formuladas são revistas, e falhas na lógica da teoria são resolvidas (COSTA, 2013; BANDEIRA DE MELO, 2006).

Como espera-se na TDF se faz necessário o movimento de ir e vir do pesquisador com os dados. Fato que permite a ressignificação do sentido e compreensão das informações coletadas até ser possível chegar ao Núcleo Central da Categoria ou Teoria Substantiva.

O movimento caracterizado por ir e vir dos dados, tem objetivo final de saturar e delinear a teoria por meio de processo analítico, e construir a teoria, dar o rigor metodológico necessário, auxiliar o pesquisador a detectar os vieses, desenvolver fundamentos, a densidade, sensibilidade e a integração necessária para gerar uma teoria (STRAUSS; CORBIN, 2008).

O Núcleo Central da Categoria poderá ou não ocorrer segundo TFD. Nesse estudo, durante a análise das entrelinhas dos discursos, após íntima aproximação da pesquisadora com os dados com intuito de extrair o significado da prática pedagógica do docente enfermeiro emergiu como essência, a fragilidade no domínio da prática pedagógica docente, distante do processo didático e dos contributos de Vigotski, denominando a categoria central "A prática pedagógica do docente distante do processo didático e dos 
contributos de Vigotski”. Vale destacar que esta categoria embora não se tenha sido planejada, despontou quase como uma validação dos dados discutidos.

$\mathrm{Na}$ teoria substantiva os discursos dos participantes selecionados evidenciaram conceitos primários ambíguos que revelaram o desconhecimento de componentes singulares ao processo didático, pertencentes aos componentes pedagógicos, ocorreram equívocos abundantes quando mencionaram a sua performance profissional durante a práxis ensino-aprendizagem, por vezes, distanciada do processo didático.

A análise dos dados e a escolha do caminho a ser percorrido são bastante subjetivas e dependem da completude do objeto de estudo, assim, há várias comparações que podem ser construídas para entender o que pode estar por trás do texto superficial. $\mathrm{O}$ pesquisador pode usar alguns para atender aos objetivos de pesquisa (STRAUSS; CORBIN, 2008).

Strauss e Corbin (1990) exemplificam técnicas que auxiliam o processo de análise:

Análise da palavra - expressão ou sentença, escolher uma palavra ou expressão que pareça importante e listar seus possíveis significados;

Técnica da Inversão - comparar os extremos em uma dimensão em questão para descobrir dimensões ou questões que não tinham sido consideradas antes;

Comparação Sistemática - utilizam-se perguntas hipotéticas para explorar todas as dimensões dos dois fenômenos, isso pode estimular o pesquisador a reconhecer o que já existe;

Comparações Distanciadas - toma um elemento do conceito que está sendo examinado e propõe o exemplo mais distante ou diferente de algum outro fenômeno que tenha algumas características em comum. Depois repasse os outros elementos de ambos os fenômenos para esclarecerem algo original. A razão da comparação é gerar mais códigos que forneçam dimensões, propriedades ou aspectos da ideia original;

Agitando a bandeira vermelha - deve-se ser sensível a expressões: nunca, sempre, não pode ser assim. Para descobrir o que aconteceria se essa situação fosse real;

Codificação linha por linha - recomendada como primeiro passo é a codificação linha por linha.

Há que se mencionar a Teoria Interpretativa, visto que essa é totalmente compatível com o Interacionismo Simbólico, pois exige compreensão imaginativa do fenômeno estudado. Essa teoria pressupõe: realidades múltiplas e emergentes, 
indeterminação, fatos e valores quando associados à verdade como algo provisório e à vida social como processo (SILVA, 2014).

A aplicação do método da TFD pode resultar um produto e ainda estabelecer modelos teóricos ou reflexões teóricas. Recomenda-se aos pesquisadores que almejam trabalhar com tal referencial metodológico o envolvimento com o objeto de estudo, disponibilidade de tempo, criatividade, domínio dos preceitos da TFD, capacidade dedutiva e indutiva e sensibilidade teórica. Essa última característica diz respeito à capacidade do investigador em perceber e compreender o significado dos dados e as habilidades em discernir entre as informações relevantes ou não ao estudo (DANTAS $e t$ al., 2009).

A partir operacionalização do percurso metodológico da TDF estimula a ousadia dos pesquisadores. Para gerir o processo de construção de uma teoria substantive é preciso buscar o equilíbrio entre o rigor científico, criatividade e inspiração em movimentos dialéticos, dotados de harmonia e conflito, sobre o que sabemos e o que achamos que sabemos. É no processo exaustivo de reconhecimento do contraditório que a teoria é enraizada e sustentada (OLIVEIRA; NAKAYAMA, 2018).

O método da TFD é relevante para a análise qualitativa, por seu rigor analítico e metodológico, em áreas como Educação, Enfermagem, Psicologia e Sociologia, têm contribuído significativamente para expansão do conhecimento a qual permite tratar a abordagem de forma interpretativa e sistemática (DANTAS et al., 2009).

\section{Considerações finais}

Este estudo caracteriza-se pela descrição da experiência da utilização da TFD na operacionalidade dos dados obtidos em uma pesquisa qualitativa. Vale destacar a relevância de disseminar junto a comunidade acadêmica que a TFD pode ser usada em pesquisa qualitativa com a finalidade de análise dos dados sem a pretensão necessária de gerar teoria, mas para análise dos dados adotando com o rigor que exige o contexto pesquisado.

Analisar os dados é um caminho subjetivo intrinsecamente ligado ao objeto de estudo, um processo que envolve sensibilidade, dedicação e criatividade, visto que o olhar do pesquisador estará voltado às entrelinhas a fim de identificar o que há por trás do texto descrito ou transcrito. Faz-se necessário identificar o que foi dito, mas não foi codificado na escrita, o sentido que os participantes da pesquisa abonam a realidade relatada. 
Recomenda-se a utilização da GroundedTheory quando há na intenção do pesquisador o desejo de desvendar um arquétipo conceitual que elucide a realidade ou aspecto dessa realidade investigado. Pois, o método permite que o pesquisador relacione os conceitos e códigos desde a codificação aberta até a codificação seletiva, enfatizando a compreensão dos aspectos investigados a medida que vão emergindo dos dados, essa característica desabilita as inferências de conceitos e teorias prévios do pesquisador, o dado assume papel de fundamentar a teoria e a análise da pesquisa.

O uso da TDF como instrumento de análise de dados, produziu experiência exitosa, permitindo que os pesquisadores pudessem mergulhar no contingente de informações e realizar o contínuo movimento de ir e vir nos dados para análise criteriosa, além de vislumbrar o surgimento da teoria substantiva na codificação seletiva a partir da discussão das subcategorias.

A utilização da TDF permitiu perceber que o processo de análise de dados subjetivos/qualitativos revela fenômenos complexos, que precisam ser compreendidos e explicados e uma pesquisa qualitativa. Portanto, é necessária relação profunda e próxima com os dados para perceber as nuances do fenômeno, essa relação pode ser medeada pela Grounded theoruy.

\section{Referências}

BANDEIRA DE MELO, R. Softwares em Pesquisa Qualitativa. In: GODOI, C. K.; BANDEIRA-DE-MELLO, R.; SILVA, A. B. da. (Org.). Pesquisa Qualitativa em Organizações: Paradigmas, Estratégias e Métodos. 1. ed. São Paulo: Editora Saraiva, 2006. p.429-460.

CASSIANI, S. H. B.; CALIRI, M. H. L.; PELÁ N. T. R. A teoria fundamentada nos dados como abordagem da pesquisa interpretativa. Revista Latino-Americana Enfermagem, Ribeirão Preto, SP, v. 4, n. 3, p. 75-88, dez. 1996.

CHARMAZ, K. A construção da teoria fundamentada: guia prático para análise qualitativa. 1. ed. Porto Alegre: Artmed, 2009.

CHENITZ, W. C.; SWANSON, J. M. From Practice to Grounded Theory: qualitative research in nursing. 1. ed. California: Addison-Wesle, 1986.

COSTA, G. S. Mobile, Mobile Learning: Explorando potencialidades com o uso do celular no ensino-aprendizagem de língua inglesa como língua estrangeira com alunos da escola pública. 2013. Tese (Doutorado em Letras) - Universidade Federal de Pernambuco, Recife, 2013.

DANTAS, C. et al. Teoria fundamentada nos dados - aspectos conceituais e operacionais: metodologia possível de ser aplicada na pesquisa em enfermagem. Revista Latino-Americana de Enfermagem, Ribeirão Preto, v. 17, n. 4, p. 573-579, jul./ago. 2009. 
FAZENDA, I. C.A. O que é Interdisciplinaridade? 2. ed. São Paulo: Cortez, 2013.

FREITAS, A. S.; BANDEIRA DE MELO, R. A Grounded Theory for managerial action in the process of e-learning implementation in business schools of Brazil. BASE-Revista de Administração e Contabilidade da Unisinos, São Leopoldo, v. 10, n. 2, p. 100-116, abr./jun. 2012.

GLASER, BG; STRAUSS, AL. The discovery of grouded theory. New York, Aldine, 1967.

LIBÂNEO, J.C. Didática como campo investigativo e disciplinar e seu lugar na formação de professores no Brasil. Currículo, didática e formação de professores. Campinas: Papirus, 2013.

OLIVEIRA, P. C.; NAKAYAMA, M. K. Operacionalização de uma groundedtheory: o percurso metodológico. Revista Pesquisa Qualitativa, São Paulo, v. 6, n. 12, p. 572-594, dez. 2018.

PESSOA, P. S.; MACEDO, E. P. Prática docente e Políticas Educacionais no Ensino Superior e os quatro pilares da Educação. Revista de Educação ANEC, Brasília, n. 157, p. 108-119, out./dez. 2018.

SILVA, C. C. Análise sistêmica do processo ensino aprendizagem de genética à luz da Teoria Fundamentada. Tese (Doutorado em Educação em Ciências e Matemática) - Rede Amazônica de Educação em Ciências e Matemática. Manaus, 2014.

SILVA, K.L. et al. Desafios da formação do enfermeiro no contexto da expansão do ensino superior. Escola Anna Nery Revista de Enfermagem, Rio de Janeiro, v. 16, n. 2, p. 380-387, jun. 2012.

SILVA, N. S. et al. Conhecimento dos coordenadores de Centros de Atenção Psicossocial sobre Política Nacional de Saúde Mental. Ciência Cuidado e Saúde, Maringá, v. 14, n. 2, p. 11061114, abr./jun. 2015.

STRAUSS, A.; CORBIN, J. Pesquisa qualitativa: técnicas e procedimentos para o desenvolvimento de teoria fundamentada. Tradução Luciane de oliveira da Rocha. 2. ed. Porto Alegre: Artmed, 2008.

TAROZZI, M. O Que É um Grounded Theory? Metodologia de Pesquisa e de Teoria Fundamentada nos Dados. 1. ed. Petrópolis: Vozes, 2011.

Recebido em: 19 de fevereiro de 2018.

Aceito em: 18 de julho de 2019. 